\title{
Erratum to: Peculiarities of the Optical and Energy Properties of Thin CdSe Films
}

\author{
G. A. Il'chuk ${ }^{a, *}$, R. Yu. Petrus' ${ }^{a}$, A. I. Kashuba ${ }^{a, b}$, I. V. Semkiv ${ }^{a}$, and E. O. Zmiiovs'ka ${ }^{a}$ \\ ${ }^{a}$ Lviv Polytechnic National University, Lviv, 79013 Ukraine \\ ${ }^{b}$ Ivan Franko National University of Lviv, Lviv, 79005 Ukraine \\ *e-mail: ilchukg@gmail.com \\ Received May 20, 2020; revised May 20, 2020; accepted May 20, 2020
}

DOI: $10.1134 / \mathrm{S} 0030400 \mathrm{X} 20060260$

Page 50, Section 2, the text in the parentheses should read Sumy, Ukraine.

The original article can be found online at https://doi.org/10.1134/S0030400X20010105 